\title{
Postaxial acrofacial dysostosis (Miller) syndrome: a
}

\section{new case}

\author{
J Vigneron, M Stricker, P Vert, J M Rousselot, M Levy
}

\begin{abstract}
We describe a new case of postaxial acrofacial dysostosis (Miller) syndrome. This syndrome consists of mandibulofacial dysostosis, similar to that seen in Treacher Collins syndrome, and postaxial limb deficiency. The mode of inheritance remains uncertain.
\end{abstract}

The infant reported here had the characteristic features of Miller syndrome; however, the initial severity of the respiratory problems is noteworthy. Family history showed no other abnormal findings. We feel that, because of the isolated nature of this case, speculation about the mode of inheritance is inappropriate. Genetic counselling requires caution and careful prenatal surveillance with ultrasonographic evaluation is indicated.

\section{Case report}

The proband, a boy, was born at 40 weeks' gestation, to healthy, non-consanguineous parents. Birth weight was $3450 \mathrm{~g}$. He measured $48 \mathrm{~cm}$ in length and had a head circumference of $36 \mathrm{~cm}$. The mother took no medication nor was she exposed to any teratogenic agent during an otherwise normal pregnancy.

Service de Médecine et Réanimation Néonatales, Maternité Régionale Universitaire, Nancy 54000, France.

J Vigneron, $P$ Vert

Service de Chirurgie Maxillo-Faciale, CHRU, Nancy 54000, France.

M Stricker

Service de Pédiatrie III, Hôpital d'Enfants, Vandoeuvre 54500, France.

J M Rousselot

Service de Pédiatrie, Hôpital Bonsecours, Metz 57000, France.

M Levy

Correspondence to Dr Vigneron, Service de Médecine Néonatale, Maternité Régionale, 54042 Nancy Cedex, France.

Received for publication 8 November 1989.

Revised version accepted for publication 30 January 1991.
At 6 months, the infant weighed $4700 \mathrm{~g}$, length $59 \mathrm{~cm}$, and head circumference $39 \mathrm{~cm}$. Examination showed global developmental delay which had evolved progressively since birth. In addition, the infant had multiple facial and limb malformations.

The facial dysmorphism was similar to that seen in Treacher Collins syndrome and included ectropion of the lower lid, malar hypoplasia, micrognathia, and microstomia. The philtrum was long and poorly formed. The ears were small, cupped, low set, and posteriorly rotated. The eyebrows were thin. Further findings included glossoptosis, cleft palate, and a very small fontanelle (fig 1).

Examination of the hands showed bilateral absence of the fifth digits. The four fingers on each hand were deviated medially and the thumbs were abnormally small (fig 2). The infant did not have either radioulnar synostosis or shortened forearms. Bilateral single palmar creases were present. In the lower limbs, the fifth toes were absent and the big toe appeared to be small.

Other anomalies included cryptorchidism and bilateral inguinal herniae. A thirteenth pair of cervical ribs and a synostosis between a right cervical and the adjacent rib were present; the latter rib was also hypoplastic. There was no pelvic dysplasia but the iliac wings were narrow and the ischiopubic bones appeared to be branched. The humeral bone shafts were short and the metaphyses had a fan-like appearance. Radiographs confirmed the absence of the fifth digits of the hands and feet bilaterally, as well as hypoplasia of the first metacarpals. The infant's karyotype was normal, 46,XY.

The infant's condition worsened because of respiratory problems which further aggravated his growth retardation. He presented with severe inspiratory dyspnoea and signs of acute respiratory failure. Since intubation was impossible, tracheostomy was performed. This resulted in dramatic weight gain. After decannulation the wound healed without complication. At 18 months, the child's psychomotor development was satisfactory. Audiometric evaluation was not performed.

Clinical evaluation of this child's parents failed to show even minor abnormal findings. Furthermore, their karyotypes were normal and study of the family history and pedigree showed no similar cases. 

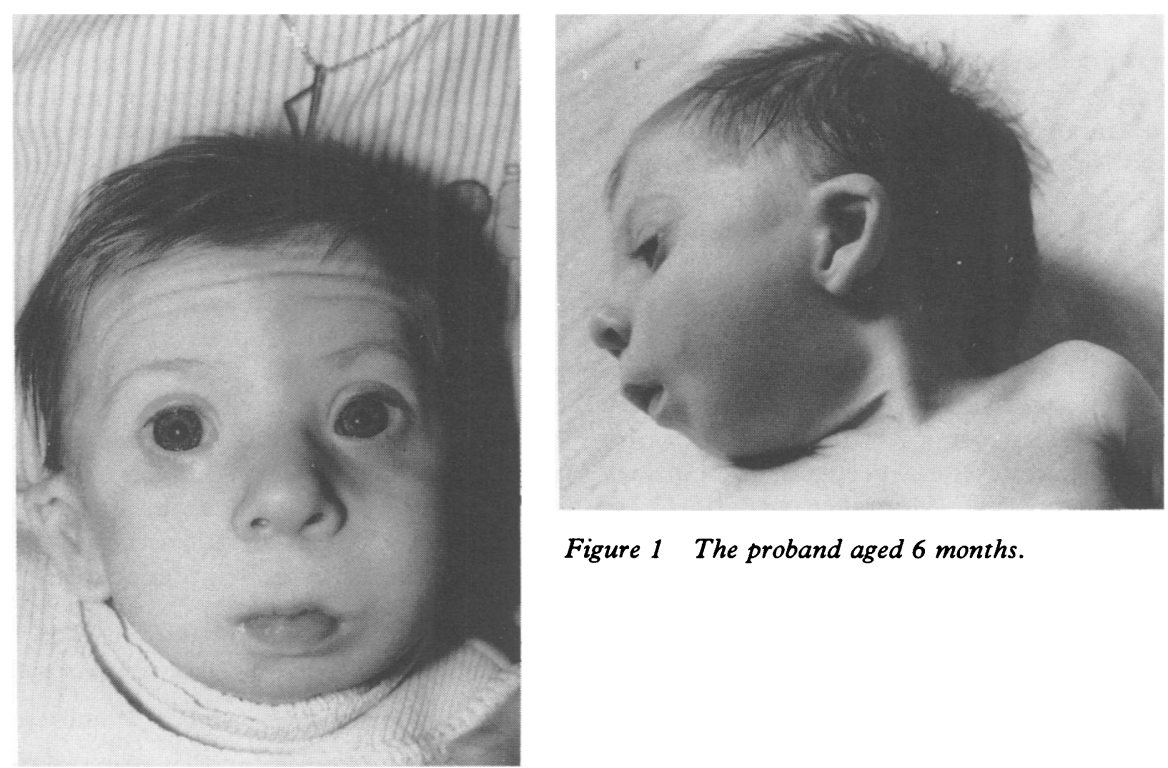

Figure 1 The proband aged 6 months.

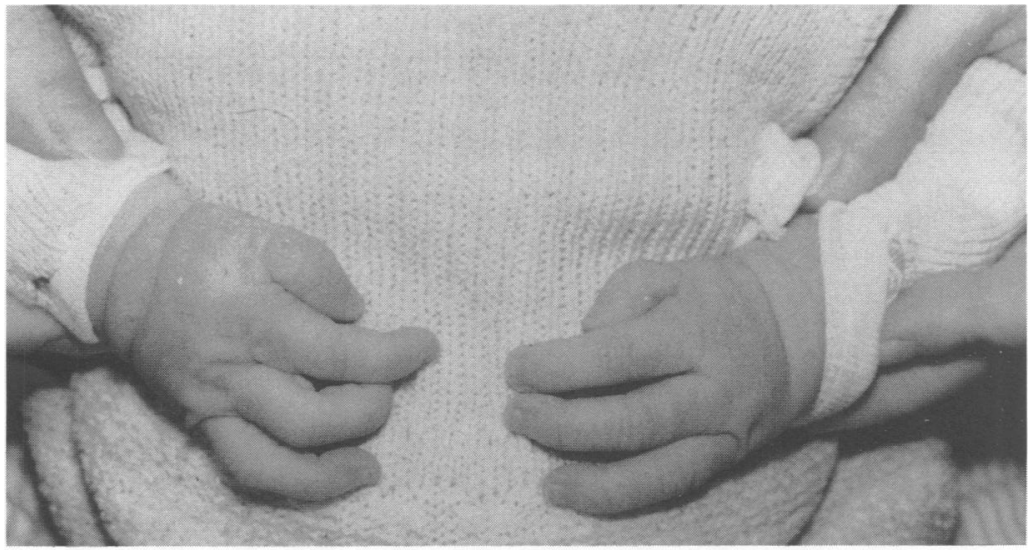

Figure 2 Hands of the proband showing absence of the fifth

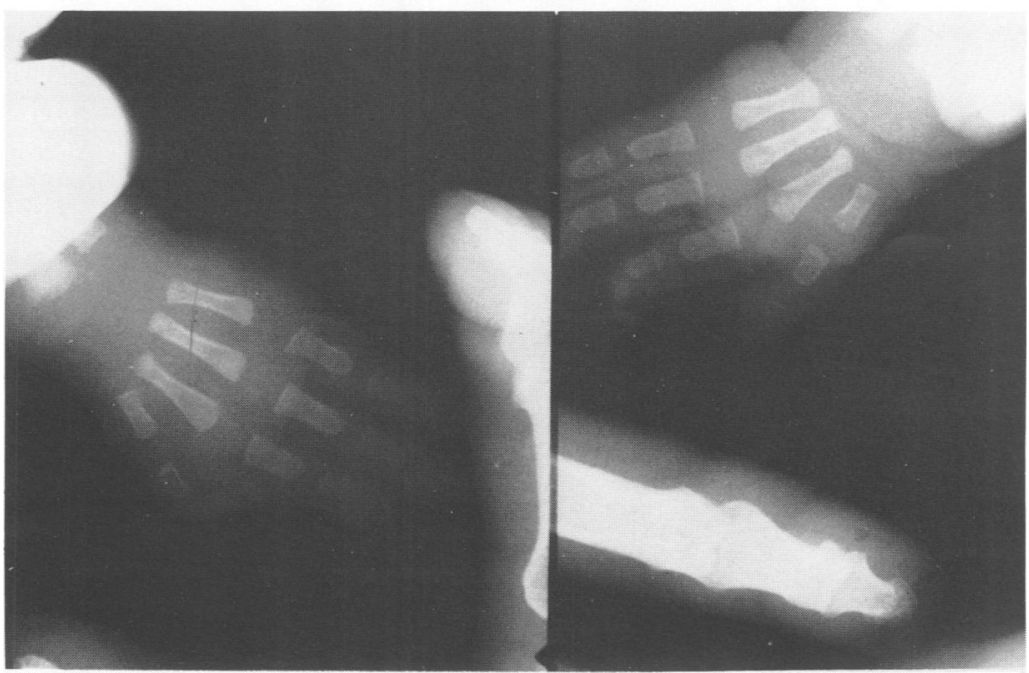
fingers. 


\section{Discussion}

In 1969, Genée$^{1}$ reported a case associating Treacher Collins type facial dysmorphism with abnormalities of the fifth digit. Since then, Miller et $a^{2}$ have reported several cases of infants presenting with postaxial acrofacial dysostosis syndrome. Four additional cases have subsequently been reported. Among them, two occurred in a sibship. ${ }^{34}$ The features of the infant reported here and those previously reported are shown in the table.

None of the 10 previously reported infants had respiratory problems as severe as those observed here. The contribution of the Pierre-Robin anomalad in this case to the severity of the clinical evolution is noteworthy. Mental retardation, an

Clinical features of postaxial acrofacial dysostosis.

\begin{tabular}{lccc}
\hline & $\begin{array}{c}\text { Published } \\
\text { cases }\end{array}$ & This report & Total \\
\hline Malar hypoplasia & 10 & + & $11 / 11$ \\
Lower lid ectropion & 10 & + & $11 / 11$ \\
Cleft lip & 2 & - & $2 / 11$ \\
Cleft palate & 9 & + & $10 / 11$ \\
Micrognathia & 10 & + & $11 / 11$ \\
Cupped ears & 10 & + & $11 / 11$ \\
Hearing deficit & 2 & $?$ & $2 / 11$ \\
Extra nipples & 5 & - & $5 / 11$ \\
Ulnar ray deficiency & 10 & + & $11 / 11$ \\
\hline
\end{tabular}

inconstant finding, was not present in this case. Since deafness is a frequently associated feature, routine audiometric evaluation is indicated.

Because so few cases have been reported, little is known concerning the inheritance of this syndrome. Males outnumber females by eight to three and the majority are the first born. In 1981, Fineman ${ }^{3}$ reported this syndrome in a brother and sister whose parents were normal. This lends support to the hypothesis of autosomal recessive inheritance, which is further supported by reports of parental consanguinity in previous cases. ${ }^{5}$ Finally, the karyotypes of all the patients were normal. ${ }^{3}$ Cautious genetic counselling is therefore advisable since recurrence cannot be ruled out and careful prenatal surveillance as well as ultrasound evaluation are indicated for subsequent pregnancies.

1 Genée E. Une forme extensive de dysostose mandibulo-faciale. $\mathcal{f}$ Genet Hum 1969;17:45-52.

2 Miller M, Fineman RM, Smith DW. Postaxial acrofacial dysostosis syndrome. $\mathcal{F}$ Pediatr 1979;95:970-5.

3 Fineman RM. Recurrence of the postaxial acrofacial dysostosis syndrome in a sibship: implications for genetic counselling. $\mathcal{F}$ Pediatr 1981;98:87-8.

4 Donnai D, Hughes HE, Winter RM. Postaxial acrofacial dysostosis (Miller) syndrome. 7 Med Genet 1987;24:422-5.

5 Chemke J, Mogilner BM, Ben-Itzhak I, Zurkowski L, Ophir D. Autosomal recessive inheritance of Nager acrofacial dysostosis. f Med Genet 1988;25:230-2. 